\title{
A Survey of Unmanned Aircraft Systems Regulation: Status and Future Perspectives
}

\author{
Konstantinos Dalamagkidis, Kimon P. Valavanis, Les A. Piegl
}

\begin{abstract}
Any aircraft, manned or unmanned, may enter safely and legally into the US National Airspace System (NAS) provided that it has been issued an airworthiness certificate complying with Federal Aviation Administration (FAA) requirements. Unfortunately corresponding requirements, procedures and regulations for airworthiness certification of unmanned aircraft are in early development stages and flight of such systems is still restricted. This paper presents a survey of the current status of Unmanned Aircraft System (UAS) regulations both in the US and internationally, followed by brief overview of current manned aviation airworthiness certification procedures and requirements. Future perspectives of UAS regulation are discussed along with a proposed UAS classification for certification purposes.
\end{abstract}

\section{INTRODUCTION}

Not long after the first flight of the Wright brothers, the need to regulate civil aviation ensuring safety and healthy competition became evident and several conventions took place to address such issues and concerns. One of the most significant took place in Chicago in 1944, right after the end of the Second World War with more than fifty States attending. The accomplishments of that conference set the groundwork for aviation safety and international cooperation on regulations, standards and procedures development, all relevant even to this day. This conference also marked the founding of the International Civil Aviation Organization (ICAO) as a means to secure progress accomplished during the conference and guarantee future cooperation [1].

Although early UAS were in operation before the Second World War, their operations were very limited and the technology started to mature much later. Nevertheless, Article 8 of the Chicago Convention refers specifically to pilotless aircrafts [2] and provisions within still apply to current systems. Some of those provisions are that a UAS cannot fly over another State without special authorization by that State (Article 8); UAS are required to bear registration marks (Article 20) and they must have a certificate of airworthiness (Article 31) [2]. Nevertheless, it should be noted that the Chicago Convention applies to civil aircraft and as a result, UAS used in military or law enforcement services could/may have additional restrictions [2].

Currently several military UAS are in service and more are under active development. Their potential has also been noticed by the public sector to the point where several organizations/agencies (including the US Coast Guard, Customs and Border Protection, Department of Homeland Security,

The authors are with the Unmanned Systems Laboratory, Computer Science and Engineering Department, University of South Florida, 4202 East Fowler Avenue, ENB 118, Tampa, FL 33620
TABLE I

NOMENCLATURE

Advisory Circular

American Institute of Aeronautics and Astronautics

Academy of Model Aeronautics

Acceptable Means of Compliance

Advance Notice for Proposed Amendment

Aviation Safety Reporting System

American Society for Testing and Materials

Civil Aviation Authority (United Kingdom)

Civil Airspace System

Civil Aviation Safety Authority (Australia)

Certificate of Authorization

Center of Excellence

Department of Defense

EASA

FAA

FAR

HALE

ICAO

IEEE

JAA

JCGUAV Joint Capability Group on Unmanned Aerial Vehicles

LSA

MASPS

MTOW

NAS

NOTAM

$\mathrm{R} / \mathrm{C}$

RTCA

SAE

STANAG

UAS

Federal Aviation Administration (US)

Federal Aviation Regulations

High Altitude Long Endurance

International Civil Aviation Organization

Institute of Electrical and Electronic Engineers

Joint Aviation Authorities (Europe)

Light-sport Aircraft

Minimum Aviation System Performance Standards

Maximum Take-Off Weight

National Airspace System

Notice to airmen

Remotely Controlled

Radio Technical Commission for Aeronautics

Society of Automotive Engineers

Standardization Agreement

Unmanned Aircraft System

Department of Agriculture as well as local law enforcement agencies) are launching initiatives to introduce UAS in their infrastructure [3]. The potential for commercial applications has not been left unnoticed either, with several million dollars of investments predicted over the coming years [4]. In the long term UAS can be expected to fully replace manned aircraft for the "dull, dirty and dangerous" missions and reduce costs for many current aviation-related operations. However, despite significant interest for commercial applications, efforts in that area are limited.

UAS technology is still new and not extensively tested, a fact that has led civil aviation authorities to be cautious with regulation development. In addition to that, this new technology is targeted for applications of a different nature than that of the majority of current aviation, which may introduce new safety issues. As a result these characteristics need to be first thoroughly investigated. It should also be noted that even compliance with current manned aviation is not without problems. Limited see and avoid capabilities; lag in communications between ATC and aircraft; and control re- 
sponse times that may not be sufficient for certain maneuvers or emergency procedures, are some examples of issues that are yet to be resolved.

As a result civil aviation authorities, including the FAA, to avoid a regulatory gap have adopted strict interim measures that significantly limit the use of UAS or even prohibit them completely. In the meantime appropriate regulation is being prepared, but it is expected to be several more years before routine civil UAS operations are possible. It should be noted that the lack of regulations has lead to situations were UAS operations are based on the wrong interpretation of FAA policies as admitted by the FAA in [5] with possible safety and security implications. It is essential therefore, not only to review the current regulatory status and existing airworthiness certification avenues available, but also evaluate any future possibilities that may be arise, allowing UAS operators to fly lawfully as well as safely in the NAS.

\section{STATUS QUO}

\section{A. International}

Currently several states including Australia, Canada, Finland, Italy, Malaysia, Sweden, UK and the US, have begun implementing procedures to issue special operating authorizations for UAS [6].

In April 2005, ICAO decided to consult with some of its member states regarding current and future UAS operations in their respective NAS, and investigate if there is a need for ICAO guidance material [6]. In this survey many states reported that they foresee international civil UAS operations in the near future [6], a fact that motivated ICAO to explore UAS regulations further. An informal, exploratory meeting followed in May 2006 in Montreal, Canada, where attending delegates of fifteen states and seven international organizations agreed that ICAO was not the appropriate body to lead the regulatory effort and that although it could guide and coordinate to some extent the regulatory efforts, the latter should be based on the work of RTCA, EUROCAE and other bodies [6]. In a second ICAO meeting during January 2007 in Florida, a UAS study group was established with the goal of supporting the regulation and guidance development within ICAO [7]. Furthermore in a working paper presented by the US in the $36^{\text {th }}$ ICAO Assembly in September of 2007 the need to amend the accident definition with occurrences involving UAS and appropriate investigation of such accidents was put forth [8].

In Europe, the JAA and Eurocontrol formed a UAV Task force that issued a report in 2004 [2] on civil UAS regulation. This was followed by an A-NPA from EASA, titled "Policy for Unmanned Aerial Vehicle (UAV) certification" [9]. In France, the French Flight Test Center adopted certification specifications for normal, utility, aerobatic and commuter manned airplanes to UAS [9]. CAA and CASA also had similar programs to regulate UAS operations in their respective airspaces [10], [11].

Japan had more than 2,000 Yamaha Rmax unmanned helicopters in service for agricultural purposes by 2002 with more added each year [3]. These systems are required to fly at a maximum altitude of $150 \mathrm{~m}$.

In the military domain, in an effort to allow UAS to fly over different states with minimal restrictions, the JCGUAV of the NATO Naval Armaments Group approved the first draft of STANAG 4671 - USAR in March of 2007 [12].

For safety reasons UAS flight in the US and worldwide is currently segregated from the rest of the air traffic with the use of NOTAMs [13].

\section{B. Light UAS}

Most of the documents previously mentioned concern civil UAS with maximum take-off weight above $150 \mathrm{~kg}$ [9], [12]. In Europe, airworthiness certification for lighter vehicles as well as public UAS remains with national authorities [9]. Although national authorities retain control for certification of vehicles lighter than $150 \mathrm{~kg}$, there is currently little or no information available on general certification requirements for this category of UAS; the only exception is a recommendation from the UK CAA that was also adopted by the JAA/Eurocontrol UAS task force [2], [14].

In the UK, the CAA has published a "Policy for light UAS systems" [14], in response to the difficulty of certifying such systems under normal policies. Eligible UAS under that policy are those that do not exhibit a maximum kinetic energy on impact over 95KJ. UAS also need be operated within $500 \mathrm{~m}$ of the pilot and at altitudes not exceeding 400 $\mathrm{ft}$ [14]. In order for such vehicles to be certified, a positive recommendation is required from an accredited organization that has inspected the design and manufacture of the vehicle followed by successful completion of a reliability flight test program [14]. Furthermore the CAA waives Certificate of Authorization (COA) requirements for UAS with weight less than $20 \mathrm{~kg}$, provided that they operate within a specified safety distance from airports, congested areas, third party vehicles, structures, etc. Finally for vehicles less than $7 \mathrm{~kg}$, most of the requirements are waived.

In Australia, CASA exempts only ultra light UAS (less than $0.1 \mathrm{~kg}$ ) and requires from the rest of the light UAS to operate away from populated areas at a maximum altitude of 400ft [13].

It is clarified that there is a difference in using the term 'light' in the airworthiness certification literature of manned aircraft versus that used for UAS. In the former category, light aircraft are those that do not exceed an MTOW of 600-650 kg depending on their use. On the other hand the aforementioned weight requirements for light UAS (less than $150 \mathrm{~kg}$ ) correspond better to the ultra light category as defined in the FAR Part 103.

\section{United States}

The first efforts towards UAV regulation were taken as early as 1991, when the FAA issued a notice for proposed rule making and formed an industry support group [15]. Over the following year work progressed mostly with development of Advisory Circulars (AC) regarding design, maintenance, 
pilot qualification and equipment requirements, among other topics.

The University of New Mexico published in 2001 the first version of the High Altitude Long Endurance, HALE, UAV Certification and Regulatory Roadmap [15], which was sponsored by the NASA Erast Project. Since then, newer versions have been published with feedback from other stakeholders. The goal of that document was to be a basis of discussion between the FAA, the industry and other stakeholders for establishing regulation for aircraft airworthiness, flight standards and air traffic that will allow safe operation of HALE UAS in the NAS. This effort was continued with the Access 5/UNITE program also sponsored and funded by NASA with participation of FAA, DOD and other stakeholders. The aim of this project was to integrate HALE UAS in the NAS [16] but it was terminated early in February of 2006 due to budgetary reasons [16].

Currently, flight of public UAS is authorized on a percase basis after a COA application. A COA is issued after submission of required documentation and an analysis performed by the FAA Air Traffic Division to determine that an equivalent level of safety with that of manned aviation can be achieved. It may contain operational restrictions and is normally effective for up to one year. Towards that end, the FAA has issued "AFS-400 UAS Policy 05-01" [17] which is used as the basis for the evaluation of applications for COA.

It should be noted though that according to that policy the FAA accepts COA applications only for public UAS. Civil UAS can get a special certificate under the experimental category with the limitations imposed for that category in FAR Part 21 [18] and possibly additional provisions set by the FAA, specifying other operational requirements [19]. Despite the regulatory problems, a significant interest for the use of UAS was demonstrated with the number of COA applications. In 2005 the FAA issued 50 COA and 55 more were issued in the first six months of 2006 [20].

Quite recently the FAA in cooperation with Lockheed Martin, begun development of a five year roadmap for integration of UAS in the NAS [21] and declared an initiative to "Develop policies, procedures, and approval processes to enable operation of unmanned aircraft systems (UAS)" for 2008 [22].

In addition, several organizations including ASTM, RTCA, SAE, AIAA and IEEE have been tasked to develop airworthiness and safety standards for UAS, to be included in the certification process for flight in NAS/CAS. Significant work has been accomplished by the ASTM and the RTCA as presented below.

1) ASTM: The ASTM F38 committee has produced more than 10 standards. One of the most known, the F2411-07 Standard Specification for Design and Performance of an Airborne Sense-and-Avoid System, has been adopted by the US DOD according to ASTM. Others include "Standard Practices for Unmanned Aircraft System Airworthiness", "Standard Practice for Quality Assurance in the Manufacture of Light Unmanned Aircraft System" and "Standard Practice for Unmanned Aircraft System (UAS) Visual Range Flight

\section{Operations".}

The ASTM through its standard practice document [23], proposes two certification pathways; type certification leading to a standard airworthiness certificate for large UAS and a "Light UAS" special airworthiness certificate similar to that for LSA. The special airworthiness certificate for the LSA category is issued by the FAA if the aircraft complies with all eligibility requirements in [24] and after the manufacturer of the aircraft provides all the necessary documents that certify compliance with industry consensus standards [25]. The only requirement mentioned by the ASTM for eligibility in the "Light UAS" category is an MTOW of at most $600 \mathrm{~kg}$. In addition to that, the ASTM is currently working on a standard guide document for mini UAS airworthiness, as well as a review of requirements for unmanned rotorcrafts

2) RTCA: In October of 2004, RTCA formed committee SC-203 with participation from government and industry representatives from several countries. The first task was to develop "Guidance Material and Considerations for UAS", a document that was issued in March of 2007. In addition to that the committee has been working on Minimum Aviation System Performance Standards (MASPS) for:

- UAS

- Command, Control and Communication Systems for UAS

- Sense and Avoid Systems for UAS

Nevertheless no such standards have been published yet.

\section{A BRIEF OVERVIEW OF AIRWORTHINESS CERTIFICATES}

In the US any aircraft that flies in the NAS, needs to carry an airworthiness certificate. According to FAA, there are two conditions that need be met in order for an aircraft to be considered airworthy; it must conform to its type certificate including any supplemental certificates, and it must be in a condition that ensures safe operation [24]. For aircraft that are not type certified, compliance with the second condition is adequate.

\section{A. Standard Certificates}

Standard airworthiness certificates are given to aircraft that comply with their type certificate in any of the categories defined in Federal Aviation Regulation (FAR) Part 21, including:

- Normal, utility, acrobatic and commuter aircraft (FAR Part 23)

- Transport aircraft (FAR Part 25)

- Normal rotorcraft (FAR Part 27)

- Transport rotorcraft (FAR Part 29)

- Manned free balloons (FAR Part 31)

In addition to the above categories, type certification is available for primary, restricted, US Army surplus and imported aircraft, as well. 


\section{B. Special Certificates}

For aircraft that do not meet requirements for a standard certificate but are still capable of safe flight, special airworthiness certificates are available [24]. There are six types of such special certificates:

- Primary: Aircraft type-certificated under the primary category (airplanes that are unpowered or single-engine, with MTOW of at most $1500 \mathrm{~kg}$ and an unpressurized cabin with a maximum capacity of 4 people).

- Restricted: The restricted type is for aircraft that have special purpose applications (agricultural, forest and wildlife conservation, weather control, aerial surveying, etc.).

- Limited: This category is for aircraft that are required to operate under certain restrictions.

- Light-sport (LSA): This category is for aircraft other than helicopters that do not exceed $600-650 \mathrm{~kg}$, have a maximum speed of not more than 120 knots and a capacity of not more than two persons. Additional requirements are made on the presence of certain equipment. The certification process includes FAA inspection of the documentation accompanying the aircraft as well as the aircraft itself. Upon successful completion of these inspections the FAA issues a special airworthiness certificate that may include operational restrictions.

- Experimental: This category is for research and development, to show aircraft compliance with a type certificate, to demonstrate functional and reliability requirements, to train flightcrews or perform market surveys. Kit-built aircraft may also qualify for an experimental certificate under certain conditions. Several operational requirements exist for experimental aircraft depending on their characteristics.

- Special flight permits: These permits are given to aircrafts that would not qualify for other airworthiness certificates, usually for flight testing purposes.

\section{Vehicles}

Certain types of aircraft like moored balloons, unmanned balloons, unmanned rockets and ultralights have been classified by the FAA as "vehicles" and, thus, are allowed to fly without an airworthiness certificate. More specifically most requirements regarding pilot certification, operating and flight rules, vehicle registration and marking, maintenance certification that are normally applicable to aircraft, do not apply for this category [25]. Nevertheless certain operational restrictions are in place. For example the following pertain to the operation of ultralight vehicles (FAR Part 103):

- Single occupant.

- Daylight operations.

- Recreation or sport purposes only.

- No flight over congested areas in cities, towns or open areas when crowds are present.

\section{R/C Models}

Model airplanes are regulated using AC91-57 on a voluntary basis and with few operational restrictions. In addition to that an independent organization, the Academy of Model Aeronautics (AMA) issues normal or restricted flight permits after inspection of the model, provides insurance for its members and organizes areas to safely practice aeromodelling. It is noteworthy that the AMA poses additional restrictions to the ones in FAA AC91-57, both in design (e.g. the weight of the models and their propulsion methods) as well as in operation [26].

Despite the fact that $\mathrm{R} / \mathrm{C}$ model airplanes have been suggested to present a mid-air collision risk to other aircraft [27], there is only a small number of incidents reported in the ASRS database, all occurred between 1993 and 1998. Furthermore, the occurrence was either due to model operators violating restrictions or because the pilot of the manned aircraft was unaware of authorized $\mathrm{R} / \mathrm{C}$ model activity.

\section{Airworthiness Regulation Development PROCESS}

There are two main models for the development of regulation; the traditional model and the "industry consensus" model. The traditional model is based on sufficiently mature technologies for which standards have been developed and possibly implemented. In this case the regulatory body undertakes the task of assessing the technology and standards available and develops appropriate regulations. Because of the aforementioned requirements this process is slow, costly and in some cases counter-productive since developed technology and standards is not necessarily adopted.

The "industry consensus model" was recently used for the regulation of the LSA category. In this case the FAA participated actively in the development of standards and as a result these standards were immediately incorporated into the regulatory framework upon publication. This approach is faster and more cost-effective, since the burden of drafting the standards is mostly with the industry.

Regardless of the actual development model used, there seems to be consensus in the literature that the airworthiness and type certification process for UAS should be based on that of manned aircraft of the same category, as defined primarily by their MTOW [2], [9], [28], [29]. This is achieved by removing the non-applicable paragraphs and adding any additional requirements where needed, just like other special aircraft categories.

\section{DISCUSSION}

A. Fundamental differences between UAS and manned aircraft

Before the discussion on the future aspects of UAS regulation, the fundamental differences between UAS and manned aviation need be presented. These differences will dictate tha nature and extend of changes required in current manned aviation regulation to accommodate UAS operations.

- Maximum take-off weight: Manned aircraft have an MTOW of at least $100 \mathrm{~kg}$ (more for powered vehicles) and up to 600 metric tons (Airbus A380). UAS span the entire spectrum from a few grams and up to 12 metric tons. 
TABLE II

UAV CATEGORIZATION FOR DIFFERENTIATION OF EXISTING SYSTEMS. SOURCE: [30]

\begin{tabular}{|c|c|c|c|c|}
\hline & Mass (kg) & Range $(\mathrm{km})$ & Flight Alt. (m) & Endurance (h) \\
\hline Micro & $<5$ & $<10$ & 250 & 1 \\
\hline Mini & $<20 / 25 / 30 / 150^{a}$ & $<10$ & $150 / 250 / 300$ & $<2$ \\
\hline \multicolumn{5}{|c|}{ Tactical } \\
\hline Close Range (CR) & $25-150$ & $10-30$ & 3.000 & $2-4$ \\
\hline Short Range (SR) & $50-250$ & $30-70$ & 3.000 & $3-6$ \\
\hline Medium Range (MR) & $150-500$ & $70-200$ & 5.000 & $6-10$ \\
\hline MR Endurance (MRE) & $500-1500$ & $>500$ & 8.000 & $10-18$ \\
\hline Low Altitude Deep Penetration (LADP) & $250-2500$ & $>250$ & $50-9.000$ & $0.5-1$ \\
\hline Low Altitude Long Endurance (LALE) & $15-25$ & $>500$ & 3.000 & $>24$ \\
\hline Medium Altitude Long Endurance (MALE) & $1000-1500$ & $>500$ & 3.000 & $24-48$ \\
\hline \multicolumn{5}{|c|}{ Strategic } \\
\hline High Altitude Long Endurance (HALE) & $2500-5000$ & $>2.000$ & 20.000 & $24-48$ \\
\hline Stratospheric (Strato) & $>2.500$ & $>2.000$ & $>20.000$ & $>48$ \\
\hline Exo-Stratospheric (EXO) & TBD & TBD & $>30.500$ & TBD \\
\hline \multicolumn{5}{|c|}{ Special Task } \\
\hline Unmanned combat AV (UCAV) & $>1.000$ & 1.500 & 12.000 & 2 \\
\hline Lethal (LET) & TBD & 300 & 4.000 & $3-4$ \\
\hline Decoys (DEC) & $150-250$ & $0-500$ & $50-5.000$ & $<4$ \\
\hline
\end{tabular}

${ }^{a}$ Varies with national legal restrictions

- Applications: The vast majority of manned aircraft are employed in point-to-point operations of transporting goods and people, while UAS may be also used for applications that require them to loiter over a specific area for several hours, even days.

- Sacrificability: A manned aircraft crash is considered a catastrophic accident that should be avoided as much as possible. In the case of UAS, it is acceptable to allow the UAS to crash in order to minimize damages to people and property.

- Awareness: The pilot of an aircraft is aware of the surroundings as well as of the performance of the aircraft. A UAS operator is limited to the information provided by instruments. In addition to that, in some cases UAS operators may operate more than one vehicles and/or may not be fully qualified pilots.

- Authority: In manned aircraft the person ultimately responsible for their operation is the pilot, when for UAS the controlling authority may reside with a remote operator or with the UAS itself. This also means that after the occurrence of non-catastrophic failures the UAS should be capable of continued safe flight and landing.

\section{B. On UAS Classification for Certification Purposes}

Manned aircraft airworthiness requirements are determined based on their class (e.g. large airplanes, sailplanes and power sailplanes, very light airplanes, etc.). Unfortunately, to this day, there is no consensus on UAS classification.

One of the most comprehensive categorizations based on weight, endurance and operational altitude has been presented in Table II including both fixed-wing and rotorcraft UAS. Although this table demonstrates the range of UAS capabilities, it is not meant for certification purposes.

A major concern during the development of UAS airworthiness regulation is to guarantee a level of safety that is at a minimum equivalent to that of manned aviation. At the same time though unnecessary restrictions need to be avoided since they impede UAS commercialization. A common metric to evaluate safety is that of expected fatalities after an accident. Fatalities may occur after a ground impact or a mid-air collision. A key factor that has been found to affect the former, is the aircraft Maximum Take-Off Weight (MTOW) [28], [29], [31], [32].

To determine the risk to human life after a UAS ground impact, the fatality expectation model proposed in [28] may be used. The model calculates the expected number of fatalities as a function of the aircraft's kinetic energy at impact, the area exposed to the crash and the population density in that area. To get a conservative estimate, the worst case between impact at two times the operational velocity, and impact at terminal velocity were used to calculate the kinetic energy imparted.

Using this model the minimum mean time between ground impact accidents $\left(\mathrm{T}_{G I}\right)$ was calculated for $43 \mathrm{UA}$ of various types and sizes to maintain an expected number of fatalities of less than $10^{-7} / \mathrm{hr}$. The latter limit is based on current manned aviation fatality rates and aims to achieve the equivalent level of safety requirement [28]. The $T_{G I}$ for each UAS is plotted with respect to the MTOW and presented in Fig. 1. An approximately linear relationship between the order of magnitude of the MTOW and the respective $\mathrm{T}_{G I}$ is evident. Although model parameters may change under different scenarios, this does not affect the aforementioned relationship.

Using Fig. 1 a natural classification of UAS may be based on the order of magnitude of their MTOW, where each 
subsequent class will require an accident rate an order of magnitude smaller than the previous.

The level of autonomy provides another way to classify UAS that is also of interest for certification purposes.

- Remotely piloted: A certified pilot remotely controls the system.

- Remotely operated: The UAS is given high-level commands (waypoints, objects to track, etc.) and its performance is monitored by a trained operator.

- Fully autonomous: The system is given general tasks and is capable of determining how to accomplish them. It can monitor its health and take remedial action after the occurrence of faults.

\section{On a UAS Certification Roadmap}

As mentioned in Section II-C, currently in the US there are only two avenues available for UAS certification. Public UAS need apply for a COA while at the same time a special certificate in the experimental category is required for civil UAS. The latter presents problems for the industry because it takes time and there are no clearly defined procedures for UAS. In addition to that experimental certificates are quite restrictive and do not permit commercial applications.

Current certification paths are counter-productive for the FAA as well. This is because significant resources are required to thoroughly investigate each application, resources that could be used to produce the required regulation [4]. Nevertheless FAA has declared a strategic target of developing Order 8130.UAS that will define procedures for obtaining experimental airworthiness certificates by the end of April 2008 [33].

Although the FAA is under pressure to present a UAS airworthiness certification roadmap, the document is still in development and currently unavailable. In addition to that,

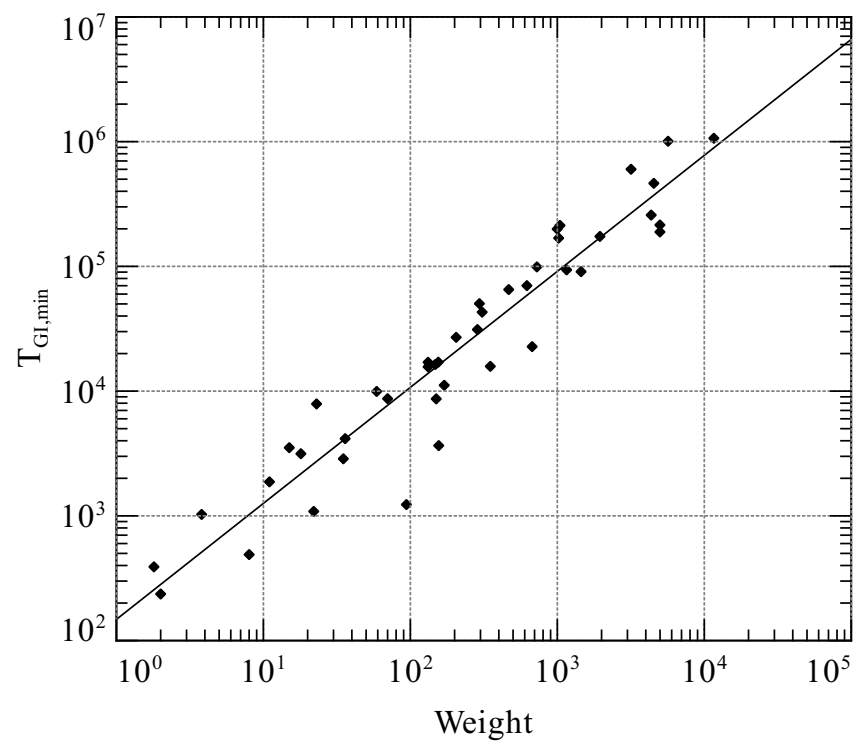

Fig. 1. The calculated $T_{G I}$ requirement versus the corresponding MTOW for 43 UAS of different types and sizes. The calculations are done for a population density of 200 people per $\mathrm{km}^{2}$.
UAS integration in the NAS is expected to take several years, since the required technology is still undergoing rapid development. Regulation development hinges on tested and verified standards for UAS that still need to be drafted.

To speed-up this process, a step-by-step integration of UAS in the NAS is proposed. Starting with small and simple designs and progressing towards larger and more complicated ones will allow fast integration of the smaller and "safer" classes. This in turn will aid the development of technology, expertise and standards that can be used to regulate the larger classes. Furthermore at first UAS can be restricted to low population/low air traffic areas but as technology matures and safety is demonstrated, this restriction can be gradually relaxed [34].

Other efforts, in parallel with standards and regulations development, are required to streamline the integration process of UAS in the NAS. Of particular importance is to collect reliable data that can be used to provide accurate information on the safety performance of UAS and their subsystems. The development of a database like the ASRS [35] is proposed to store flight logs as well as incident and accident reports. The dissemination of information will prove invaluable for UAS developers and operators and will provide insight to standardization and regulatory efforts. Furthermore insurance providers will require such information before providing liability coverage for damages incurred from UAS operations [36].

Also important is the founding of test centers where UAS components as well as whole systems will be evaluated for $\mathrm{R} \& \mathrm{D}$ and later for certification purposes. Recently the UAS CoE of the University of North Dakota expressed an interest for building such a test center [37].

Currently regulations involving public and civil UAS operations are in their early stages of development. However, there is also considerable activity in Universities, research labs and commercial entities that has resulted in a significant number of civil UAS in various stages of development. People and organizations involved in UAS activities should consult with their corresponding civil aviation authorities and be aware of current policies and the limitations imposed therein.

\section{The future}

Although it is difficult to predict the exact form of future regulations, safe assumptions can be made on certain aspects of it. The primary goal of UAS regulation will be to ensure the safety of the public and this will entail increased reliability, fault tolerance and fail-safe systems.

Effective see-and-avoid technology is also required to ensure the safety of manned aviation and minimum performance requirements from such systems are highly anticipated. In addition to that compatible collision avoidance systems like TCAS II and ADS-B may also be required for certain operation types. Besides avoiding other aircraft UAS should be also capable of following right-of-way rules, as any other aircraft. 
Another area of key importance is the reliability and security of the communications link. Already there is talk in ICAO, EUROCONTROL, FAA, RTCA and EUROCAE on a bid for UAS spectrum allocation during the 2011 World Radio Conference [38]. In addition to standards regarding the specifications of the communications channel, future airworthiness regulations will also likely require that after loss of the communications link, the UAS should be capable of continued safe flight and controlled flight termination with minimal risk to other aircraft or people on the ground.

Operation rules will be the same or similar to that of manned aviation which means that UAS will need to be capable of communicating with ATC and responding to instructions in a timely manner. UAS operations should also cause no disruption to manned aviation operations. This means that UAS will have to be compatible with the current air traffic management system without affecting its capacity. As a result in the future, UAS are unlikely to receive special separation, prioritization or other air traffic services with respect to other air traffic.

Finally, the differences in operational characteristics are also likely to lead to a different pilot certification class, with different training requirements.

As a result UAS research and development should focus on the enabling technologies that will likely be required for civil UAS operations, once the regulatory framework is in place.

\section{REFERENCES}

[1] International Civil Aviation Organization (ICAO), "Webpage of," Dec 2007. [Online]. Available: http://www.icao.int

[2] Joint JAA/Eurocontrol Initiative on UAVs, "A concept for european regulations for civil unmanned aerial vehicles (UAV)," Final Report, May 2004

[3] S. Zaloga, "Getting civil with UAVs: How soon?" Unmanned Systems, vol. 25 , no. 3, pp. 24-26, May/June 2007.

[4] S. Anand, "Domestic use of unmanned aircraft systems: Evaluation of policy constraints and the role of industry consensus standards," Journal of Engineering and Public Policy, vol. 11, 2007.

[5] Federal Aviation Administration, "Unmanned aircraft operations in the national airspace system," Docket No. FAA-2006-25714, Feb. 2007.

[6] International Civil Aviation Organization (ICAO), "ICAO exploratory metting on UAVs," Working Paper 2, The Sixteenth Meeting of the APANPIRG ATM/AIS/SAR Sub-Group (ATM/AIS/SAR/SG/16), June 2006.

[7] - "Progress report on unmanned aerial vehicle (UAV) work," AFI Planning and implementation regional group sixteenth meeting (APIRG/16), Nov 2007

[8] — "Addressing unmanned aircraft system (UAS) accident investigation and prevention by ICAO member states," Working Paper 217, ICAO 36th Assembly, Sep 2007.

[9] European Aviation Safety Agency (EASA), "A-NPA, No. 16/2005, policy for unmanned aerial vehicle (UAV) certification," 2005.

[10] Directorate of Airspace Policy, CAA, "CAP 722, unmanned aerial vehicle operations in UK airspace - guidance," Nov 2004.

[11] Office of Legal Counsel, Civil Aviation Safety Authority (CASA), "CASR part 101, unmanned aircraft and rocket operations," Jan 2003.

[12] Joint Capability Group on Unmanned Aerial Vehicles, "STANAG 4671 - Unmanned Aerial Vehicle Systems Airworthiness Requirements (USAR)," NATO Naval Armaments Group, draft, Mar 2007.
[13] FSF editorial staff, "See what's sharing your airspace," Flight Safety Digest, vol. 24, no. 5, pp. 1-26, May 2005

[14] D. R. Haddon and C. J. Whittaker, "UK-CAA policy for light UAV systems," UK Civil Aviation Authority, pp. 79-86, May 2004.

[15] New Mexico State University, Unmanned Aerial Vehicle Technical Analysis and Applications Center, "High altitude long endurance unmanned aerial vehicle - certification and regulatory roadmap," Version 1.3, 2002. [Online]. Available: http://www.psl.nmsu.edu/uav/ roadmap/

[16] Access 5, "Home page," No longer available, 2006. [Online]. Available: http://www.access5.aero/

[17] Federal Aviation Administration, "AFS-400 UAS policy 05-01, unmanned aircraft systems operations in the U. S. national airspace system," Interim Operational Approval Guidance, Sep 2005.

[18] —, "Unmanned aircraft systems (UAS) questions and answers," Retrieved, Nov 2007. [Online]. Available: http://www.faa.gov/aircraft/ air_cert/design_approvals/uas/uas_faq/

[19] D. Hempe, "Unmanned aircraft systems in the united states," Presented to the US/Europe International Safety Conference, June 2006.

[20] T. J. Zinser, "Observations on faa's oversight of aviation safety," Statement of the Acting Inspector General, US DOT before the Commitee on Transportation and Infrastructure, Subcommittee on Aviation, US House of Representatives, Sep 2006.

[21] Washington Watch, "FAA roadmap for UAS," Unmanned Systems, vol. 25 , no. 1 , p. 51, Jan/Feb 2007.

[22] Federal Aviation Administration, "FAA flight plan 2008-2012: Charting the path for the next generation," 2007.

[23] ASTM International, "Standard practice for application of federal aviation administration (FAA) federal regulations part 21 requirements to unmanned aircraft systems (UAS)," Standard F 2505 - 07, Aug 2007.

[24] Federal Aviation Administration, "Airworthiness certification of aircraft and related products," Order 8130.2F, Nov 2004

[25] R. Schultz, "Ultralights, LSAs and kit airplanes - what's the difference?" Florida Aviation and Business Journal, Sep 2006. [Online]. Available: http://www.airportjournals.com/Display. cfm?varID=0609005

[26] Academy of Model Aeronautics, "2008 official national model aircraft safety code," Effective January 1, 2008, 2007.

[27] R. E. Weibel, "Safety considerations for operation of different classes of unmanned aerial vehicles in the national airspace system," Master's thesis, Massachusetts Institute of Technology, June 2005.

[28] K. Dalamagkidis, K. P. Valavanis, and L. A. Piegl, "On safety and reliability requirements for integration of civil unmanned aircraft in the national airspace system," 2008, submitted for review.

[29] D. R. Haddon and C. J. Whittaker, "Aircraft airworthiness certification standards for civil UAVs," UK Civil Aviation Authority, pp. 79-86, August 2002.

[30] P. van Blyenburgh, "UAV systems: Global review," presented at the Avionics '06 Conference, Amsterdam, the Netherlands, Mar 2006.

[31] R. E. Weibel and R. J. Hansman, "Safety considerations for operation of different classes of uavs in the nas," in AIAA 4th Aviation Tehcnology, Integration and Operations Forum, AIAA 3rd Unmanned Unlimited Technical Conference, Workshop and Exhibit, Sep. 2004.

[32] R. Clothier and R. Walker, "Determination and evaluation of uav safety objectives," in 21 st International Unmanned Air Vehicle Systems Conference, 2006, pp. 18.1-18.16.

[33] Federal Aviation Administration, "Aviation safety fiscal year 2008 business plan," Nov. 2007.

[34] B. Davis, "Students recommend a way ahead for UAVs in the NAS," Unmanned Systems, vol. 25, no. 5, p. 23, Sep/Oct 2007.

[35] NASA, "ASRS - Aviation Safety Reporting System," Dec. 2007. [Online]. Available: http://asrs.arc.nasa.gov/

[36] J. Montgomery, "Opening civil airspace to unmanned aerial systems," Unmanned Systems, vol. 24, no. 4, pp. 35-38, July/Aug 2006

[37] B. Davis, "North dakota promotes unmanned systems at second action summit," Unmanned Systems, vol. 25, no. 3, p. 52, May/June 2007.

[38] D. Donnithorne-Tait, "Responding to standardization challenges of the future air transport system," Presented at the ICAS Workshop on "UAV Airworthiness, certification and access to the airspace, Sep 2007. 